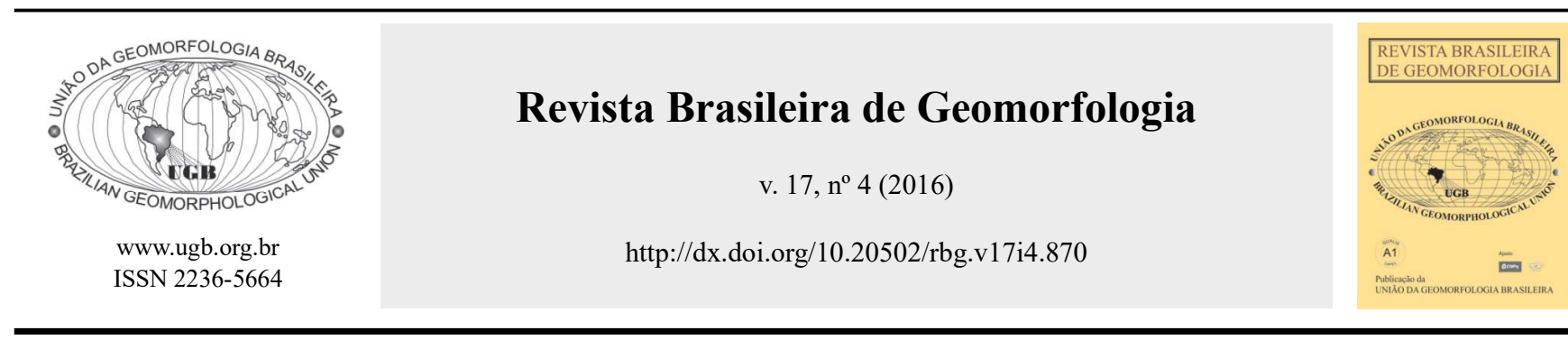

\title{
CARACTERIZAÇÃO DA REDE DE DRENAGEM E DO SISTEMA LACUSTRE DA BACIA DO RIO GRANDE: OESTE DA BAHIA - REGIÃO DO MÉDIO SÃO FRANCISCO
}

\section{CHARACTERIZATION OF DRAINAGE AND LACUSTRINE SYSTEM OF THE RIO GRANDE BASIN: WEST BAHIA - REGION OF MIDDLE SÃO FRANCISCO RIVER}

\author{
Gisele Barbosa dos Santos \\ Curso de Geografia, Universidade Federal do Oeste da Bahia \\ Rua Professor José Seabra de Lemos, 316, Recanto dos Pássaros, Barreiras, Bahia, CEP: 47.808-021, Brasil \\ Email: gisele.barbosa@ufob.edu.br \\ Paulo de Tarso Amorim Castro \\ Departamento de Geologia, Universidade Federal de Ouro Preto \\ Campus do Morro do Cruzeiro, S/N, Ouro Preto, Minas Gerais, CEP: 35400-000, Brasil \\ Email: paulo_de_tarso@degeo.ufop.br
}

\section{Informações sobre o Artigo \\ Recebido (Received): \\ 06/06/2016 \\ Aceito (Accepted): \\ $12 / 10 / 2016$}

\section{Palavras-chave:}

Morfotectônica; Lito-estrutura; Sensoriamento Remoto.

\section{Keywords:}

Morphotectonic; Lithostructure; Remote Sensing.

\section{Resumo:}

O sistema lacustre da bacia do rio Grande situa-se em um local que reúne particularidades do ponto de vista geológico e geomorfológico, no noroeste do Cráton do São Francisco. A partir da investigação de elementos morfoestruturais, pretendeu-se apresentar um panorama da geomorfologia deste sistema. Mediante o uso de técnicas de sensoriamento remoto, procurou-se estabelecer a influência da litologia e da tectônica na dinâmica atual da rede de drenagem e do sistema lacustre. Os resultados revelaram a presença de feições como anomalias de drenagem, assimetria de bacias, confinamento de planícies aluviais, diferenças bruscas de densidade de drenagem e distinção na distribuição de lagoas quanto à forma e dimensão. A área do sistema lacustre foi compartimentada em dois domínios: Domínio I com morfoestruturas NW-SE e Domínio II com predomínio de morfoestruturas NE-SW e, subordinadamente E-W, concordantes com orientações dos falhamentos regionais, o que mostra que a reativação de antigas falhas e o contexto litológico são importantes fatores para a origem e desenvolvimento deste sistema lacustre.

\section{Abstract:}

The lacustrine system of the rio Grande basin takes place in an area that gathers particularities of both geological and geomorphological points of view at the northwest craton of São Francisco River. From the investigation of morphostructural elements, it was intended to present a geomorphology's view of this system. By using the remote sensing techniques, it was sought to establish 
the influence of both lithology and tectonics in the current dynamics of the drainage and the lacustrine system. The results showed the presence of features like drainage anomalies, basins asymmetry, flood plains confinement, sudden differences of drainage density, and the distinction of lakes distribution in terms of form and dimension. The lacustrine system area was compartmentalized into two domains: Domain I with NW-SE morphostructures, and Domain II with the predominance of NE-SW morphostructures and E-W subordinately, concordant to orientations of regional failures, what shows that the activation of ancient failures and the lithological context are important factors for the origin and development of this lacustrine system.

\section{Introdução}

Na porção noroeste do Cráton do São Francisco, região oeste do Estado da Bahia, nos municípios de Santa Rita de Cássia e Cotegipe, ocorrem depressões no relevo em coberturas arenosas inconsolidadas, não conectadas com a drenagem atual, formando lagoas perenes e intermitentes. Feições semelhantes situadas em outras áreas do Brasil e do mundo, em contextos litológicos e climáticos diversificados foram foco de vários estudos. Há por exemplo, no município de Jaíba-MG, depressões em domínio de sedimentos arenosos sobrejacentes a rochas metapelíticas e carbonáticas do Grupo Bambuí, associadas à combinação de dissolução e de fatores tectônicos, estratigráficos, faciológicos e litológicos (SILVA, 1984). Ainda em Minas Gerais, na Serra da Piedade, região do Quadrilátero Ferrífero, Pereira et al. (2012) identificaram depressões fechadas em formações ferríferas bandadas resultantes da dissolução mais intensa da banda silicosa em relação à banda composta por ferro em itabiritos. Processo semelhante foi relatado por Noronha (2009) ao investigar o sistema lacustre existente em Palmeirópolis - TO, e Costa et al. (2005) na Amazônia brasileira, onde as depressões formam lagoas originadas a partir da dissolução da matriz internodular de couraças lateríticas.

No Platô de Itapetininga-SP, Castro (1980) evidenciou a presença de depressões sobre rochas basálticas da Formação Serra Geral. Já Maciel Filho et al. (2013) descreveram depressões semelhantes na região limítrofe do Rio Grande do Sul e Santa Catarina no mesmo contexto geológico. Para estes autores, a origem das depressões é resultado da alteração da rocha por dissolução do vidro vulcânico, principalmente da sílica por ser um processo que reduz o volume do material rochoso causando subsidência no terreno. Tais trabalhos evidenciam que lineamentos estruturais são considerados um gatilho para a percolação da água e, consequentemente, para os processos de dissolução. Em superfície plana de mesetas basálticas do Platô de Somuncurá, no sul da Patagônia argentina, há depressões fechadas quase circulares ocupadas por lagoas e depósitos sedimentares identificados por Corbella e Lara (2008). Neste caso, a dissolução ocorre em rochas subjacentes por vezes controladas tectonicamente, formando uma cavidade abaixo dos basaltos que, sem apoio mecânico, entra em colapso formando a depressão. As depressões relacionadas aos processos de colapso e dissolução do carste encoberto por arenitos foram registradas por Sallun Filho e Karmann (2007) em Ponta Grossa-PR e Jardim-MS, e por Nascimento e Morais (2012) em carste encoberto por filitos e metarcóseos no município de Lagoa da Confusão, no Estado de Tocantins. Já Hardt (2011), ao estudar a origem de depressões na superfície preenchidas por água na Serra de Itaqueri-SP, afirma que são feições provenientes do processo da dissolução parcial dos grãos de quartzo em arenito afetado por lineamentos estruturais. Em outro contexto, Mateus et al. (2016), ao estudarem depressões fechadas em crostas bauxíticas no município mineiro de Espera Feliz, salientam que as feições são resultantes de adelgamento pedogenético e não por aprofundamento do embasamento regional.

Depressões rasas em depósitos inconsolidados, originárias de processos de deflação combinados ou não à dissolução, ou seja, mobilização por eluviação de partículas finas para subsuperfície e acúmulo de grãos de areia soltos, os quais são facilmente transportados pelo vento, são explicações recorrentes em diversos trabalhos como, por exemplo, os de Pillmore (1976), quanto aos estudos de pequenas bacias de deflação no Novo México - EUA; Latrubesse e Nelson (2001), quanto às análises de depressões formadoras de lagoas em paleodunas altamente erodidas encontradas nas proximidades do rio Cauamé, no Estado de Roraima; e os de Christiansen e Hamblin (2014), referentes aos estudos nas planícies do Texas - EUA.

São poucos os estudos sob a ótica morfotectônica e morfoestrutural relacionados à origem das depressões formadoras do amplo sistema lacustre na porção noroeste do Cráton do São Francisco. Alves (2011) sugere que as lagoas foram formadas pela ação eólica durante processos de deflação relacionados ao clima árido no Holoceno. Caxito (2010) e Carvalho Júnior et al. (2014), ao realizarem mapeamentos na região, referiram-se aos lagos como feições de abatimento circulares, interpretadas 
como feições cársticas (dolinas) nos calcários do Grupo Bambuí, sob a fina cobertura sedimentar cenozoica.

Devido à carência de estudos com enfoque geomorfológico sobre estas feições, o presente artigo tem por objetivo investigar as principais geoformas associadas ao sistema lacustre que permitam a interpretação de possíveis controles morfoestruturais e morfotectônicos, dentro do contexto regional do Cráton do São Francisco. Cotton (1968) indica que trabalhos de investigação morfoestrutural devem ser aplicados a análises em escala regional, relacionando o controle da estrutura geológica subjacente ao arranjo das feições morfológicas existentes. Já a morfotectônica busca avaliar a relação existente entre tectônica recente ou ativa às feições morfológicas (COTTON, 1968; DOORNKAMP, 1986; SAADI, 1991; SUMMERFIELD, 1991). Seguindo estes procedimentos, investigou-se o comportamento da rede de drenagem e das bacias hidrográficas, a orientação do eixo longitudinal e da morfometria das lagoas, e o mapeamento dos lineamentos regionais da bacia do rio Grande, que podem refletir características do terreno bem como processos de reativações crustais (SOUZA FILHO et al.., 1999; STEWART e HANCOCK, 1994; GROHMANN, 2005).

Por se tratar de uma ampla área plana com cobertura arenosa (Figura 1) e ausência de afloramentos rochosos, desprovida de estradas pavimentadas e com vegetação fechada de caatinga arbustiva espinhosa, o acesso em campo a estas lagoas torna-se mais difícil, sendo mais relevante o uso do sensoriamento remoto e da cartografia, no que tange à correlação entre os fenômenos de superfície e os mecanismos de subsuperfície. Estas ferramentas têm subsidiado pesquisas geomorfológicas no território brasileiro que possuem características fisiográficas complexas como a região amazônica e a vasta região deprimida com grande volume de sedimentos do Pantanal, como atestam Hayakawa e Rossetti (2012) e Zani et al. (2012). Ademais, em áreas de paisagens cársticas, onde as investigações de padrões subterrâneos apresentam dificuldades em termos de custo e acesso, é comum o uso de fotografias aéreas, mapas topográficos, imagens de satélite e radar (HUANG, 2007).

\section{Área de estudo e contexto fisiográfico}

A área de estudo contempla a média bacia hidrográfica do rio Grande, o principal afluente da margem esquerda do rio São Francisco em seu médio curso. Esta área da bacia possui uma extensão de $8.272 \mathrm{~km}^{2}$ nos baixos cursos dos rios Preto e Camboeiro, e no médio curso do rio Grande (Figura 1).
Afloram na região conjuntos litológicos que estão associados a quatro contextos tectônicos distintos: 1rochas formadas antes do ciclo orogenético Brasiliano, representadas pelas rochas do Complexo Cristalândia do Piauí, e Formação Formosa; 2 - rochas formadas em riftes neoproterozoicos, representados pela Formação Canabravinha e o Grupo Santo Onofre; 3 - rochas formadas em contexto de bacia de antepaís decorrente de afundamento crustal relacionado aos orógenos Brasília e Araçuaí, representados pelas rochas do Grupo Bambuí (formações Riachão das Neves, Serra da Mamona, São Desidério); 4- rochas formadas na Bacia Sanfranciscana, do Mesozoico, representadas pelo Grupo Urucuia. Superpostos parcialmente aos três primeiros contextos tectônicos assentam-se sedimentos neogênicos e quaternários do médio rio Grande, restritos em área à região entre a garganta da Serra do Boqueirão e o Chapadão do Urucuia, onde está situado o sistema lacustre.

No contexto pré-Brasiliano, o embasamento cratônico, porção da litosfera continental formada desde o Arqueano (ALKMIM, 2004), aflora a nordeste da região, composto por intercalações entre biotita-gnaisses e anfibolitos, e por uma associação entre granitos, gnaisses e migmatitos (EGYDIO-SILVA,1987) representado pelo Complexo Cristalândia do Piauí (ARCANJO e BRAZ FILHO, 1994). Ao norte afloram rochas da Formação Formosa, composta por micaxisto (granada), quartzito micáceo, metachert ferro-manganesífero, epidoto-actinolita-clorita xisto (xisto verde), e localmente, intercalações concordantes de orto-anfibolito e por quartzito lítico, conglomerático, feldspático, carbonático e/ou micáceo (UHLEIN et al., 2011).

No contexto de riftes e aulacógenos neoproterozoicos, no limite noroeste, afloram os metadiamictitos, metarenitos e metamargas da Formação Canabravinha, retrabalhados no ciclo Brasiliano (CAXITO et al., 2012). A leste, na Serra do Boqueirão, que compõe o Espinhaço Setentrional, afloram rochas pertencentes ao Grupo Santo Onofre que, de acordo com Uhlein et al. (2004), é constituído por metabrechas, quartzitos e metarritmitos (ARCANJO e BRAZ FILHO, 1994; SCHOBBENHAUS, 1996).

No Contexto da Bacia de Antepaís, a área cratônica serviu de base para as rochas neoproterozoicas do Grupo Bambuí, que afloram na média bacia do rio Grande. São representadas em sua base por calcários cinza-escuros intercalados a margas e siltitos da Formação São Desidério, por metarcóseos e metarenitos, com lentes de metamargas e metacalcários da Formação Riachão das Neves e por metassiltitos, ardósias e metacalcários 
intercalados a metarenitos finos da Formação Serra da Mamona (EGYDIO-SILVA, 1987).

No contexto da Bacia Sanfranciscana, em toda a porção oeste e sul da área de estudo afloram um conjunto de rochas siliciclásticas, de idade cretácea, formado por conglomerados, arenitos e siltitos do Grupo Urucuia (SPIGOLON e ALVARENGA, 2002).

Geomorfologicamente, a área de estudo possui quatro unidades distintas:

- o Chapadão do Urucuia ou Chapadão Ocidental da Bahia, que ocupa toda a porção oeste da bacia e extremos norte e sul, cuja altitude varia de 700 a 1000 metros aproximadamente, com uma declividade de no máximo $3 \%$, constitui superfícies estruturais relacionadas a rochas com acamamento sub-horizontal do Grupo Urucuia (GROHMANN e RICCOMINI, 2012);

- os Planaltos em Patamares ocorrem na borda leste do Chapadão do Urucuia, possuem maiores declividades, apresentam relevo forte ondulado e montanhoso (20 a
$75 \%$ de declividade) com altitudes que variam de 500 a 700 metros. Nesta unidade predominam processos de dissecação, onde afloram as rochas do Grupo Bambuí, apresentando feições como escarpas, colúvios e formas ruiniformes;

- a Depressão do São Francisco, que ocupa toda a porção central da bacia, apresenta altitudes de 380 a 500 metros e declividade de 3 a $8 \%$. Trata-se de uma zona de acumulação de sedimentos areno-argilosos neogênicos e quaternários provenientes das unidades mais elevadas em relação ao seu entorno. Todo o sistema lacustre está inserido nesta unidade apresentando um desnível altimétrico de 110 metros, como ilustra o perfil topográfico na figura 1 ;

- a Serra do Boqueirão (Espinhaço Setentrional) possui morfologia geral de um espigão pronunciado, marcado por paisagens de estreitas faixas de campos de altitude, com elevações que podem chegar a 1000 metros de altitude e declividades superiores a 75\% (ALKMIM, 2012).
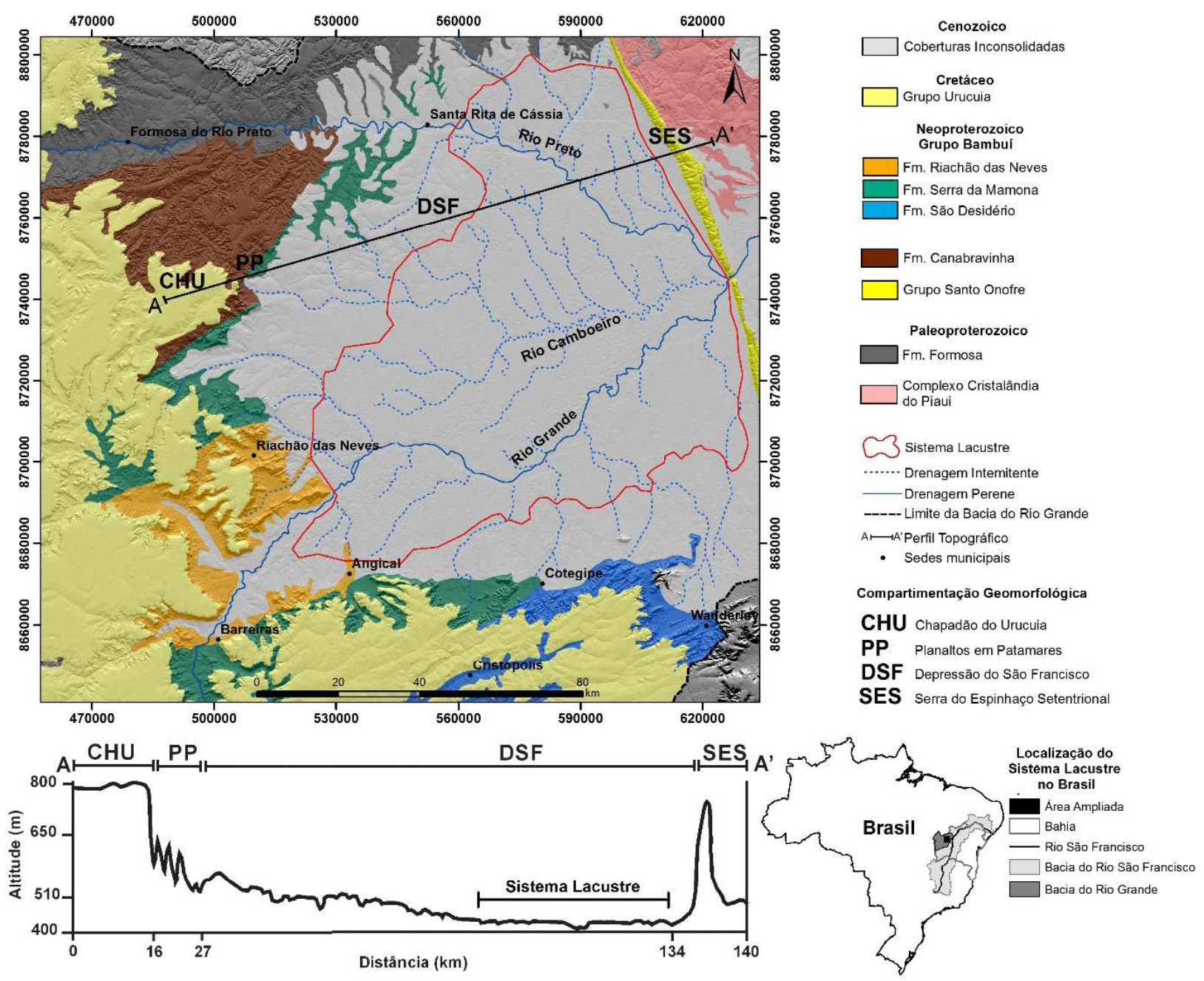

Figura 1 - Localização do sistema lacustre, por meio de MDE-Topodata, com as principais drenagens, geologia e relevo da área de estudo (Adaptado do Banco de dados do Serviço Geológico do Brasil (CPRM), disponivel em http://geobank.sa.cprm.gov.br/. 
O clima da região é do tipo $A w$, segundo classificação de Köppen, com duas estações bem definidas: verão chuvoso, que se estende de outubro a abril, e inverno seco, de maio a setembro, cujas temperaturas médias variam entre $26^{\circ}$ e $20^{\circ} \mathrm{C}$ (GASPAR, 2006). A umidade relativa do ar para toda a bacia do rio Grande possui os maiores índices de novembro a maio, sendo março o mês que apresenta o maior índice médio $(79,9 \%)$, enquanto o mais seco é setembro, com $47,1 \%$. Os índices pluviométricos anuais variam de 800 a $1100 \mathrm{~mm}$ (subúmido) (MOREIRA e SILVA, 2010). A vegetação da bacia do rio Grande apresenta o Cerrado como bioma predominante, ocupando toda a porção oeste. A porção centro-leste, onde se localiza o sistema lacustre, se configura uma área de transição entre o Cerrado e a Caatinga denominada «Área de Tensão Ecológica" de acordo com a classificação dos Biomas Brasileiros do IBGE (1992).

\section{Material e Métodos}

Foram utilizadas diferentes escalas e métodos de sensoriamento remoto para subsidiar análises sobre a influência do controle estrutural na rede de drenagem e especificamente sobre o sistema lacustre.

Para essas análises foram utilizados: dados do Modelo Digital de Elevação MDE-SRTM TOPODATA com 30 metros de resolução espacial (VALERIANO e ROSSETTI, 2012/www.dsr.inpe.br/topodata), disponibilizados para todo o território brasileiro; imagens do satélite RapidEye com 5 metros de resolução espacial; e bases litológicas e hidrográficas adquiridas e adaptadas do banco de dados do Serviço Geológico do Brasil (CPRM/ http://geobank.sa.cprm.gov.br/.).

Para o cálculo da superfície de tendência foi utilizado o método descrito por Zani et al.. (2012), esta ferramenta tem obtido êxito em estudos geomorfológicos que necessitam realçar geoformas positivas ou negativas em amplas áreas homogêneas com baixa amplitude altimétrica (GROHMANN et al., 2007; ROSSETTI e VALERIANO, 2007; HASHIMOTO et al., 2008; GHONEIM, 2009; ROSSETTI et al., 2011; ZANI et al., 2012). Utilizando o ArcGis 10.1., fez-se um mosaico das imagens SRTM e criou-se um polígono limitando o sistema lacustre. A partir daí foram geradas superfícies de tendência com polinômios de graus 1 a 9, e realizado o teste de coeficiente de ajuste $\left(\mathrm{R}^{2}\right)$ para indicação da melhor adequação do grau do polinômio aos dados originais. Após esta etapa foi realizada subtração do raster representado pela superfície de tendência com melhor ajuste pela SRTM original. Esta operação resultou em uma imagem de resíduos com os valores de altitude referenciada pela superfície de tendência onde elevações residuais positivas estão acima da tendência e as negativas, abaixo, resultando em um MDE aprimorado.

Para o cálculo de parâmetros morfométricos foram criados polígonos das lagoas delimitados manualmente por meio das imagens RapidEye. Posteriormente, foram calculados a Área (A), o Perímetro (P), e a Forma (F). Os dois primeiros cálculos foram obtidos automaticamente pela ferramenta Calculate Geometry do ArcGis 10.1. O cálculo da Forma $(\mathrm{F})$ foi realizado a partir da mesma ferramenta por meio da inserção da fórmula: $F=$. Este índice demonstra o grau de irregularidade das margens de um lago, cuja classificação se baseia nas seguintes classes de valores: Forma Circular $(2 \leq \mathrm{F} \leq 2,59)$; Forma Alongada $(2,6 \leq F<3)$; e Forma Coalescente $(F \geq 3)$ (LÜBBE, 1977 apud STRASKRABA e GNAUCK, 1982). O polígono das lagoas alongadas e coalescentes foi utilizado para gerar uma representação pontual a partir de seu centróide com a ferramenta feature to point (ArcGis 10.1). Os parâmetros: comprimento máximo $\left(\mathrm{L}_{\max }\right)$; e largura máxima $\left(\mathrm{La}_{\max }\right)$ foram traçados passando pelo centróide de cada lagoa.

$\mathrm{O}$ cálculo da assimetria de bacias de drenagem foi feito utilizando-se a fórmula: $\mathrm{AF}=100 \mathrm{x}(\mathrm{Ad} / \mathrm{At})$, onde $\mathrm{AF}=$ fator de assimetria, $\mathrm{Ad}=$ área direita da bacia de drenagem, e At=área total da bacia de drenagem (MANTELLI e ROSSETTI, 2009). A densidade de drenagem é a relação entre o comprimento dos canais e a área da bacia hidrográfica. Este índice é importante para o estudo dos diversos controles atuantes sobre a drenagem e foi obtido através da fórmula: $\mathrm{Dd}=\mathrm{Lb} / \mathrm{At}$, onde $\mathrm{Dd}=$ densidade de drenagem; $\mathrm{Lb}=$ comprimento total dos rios ou canais existentes na bacia; $\mathrm{At}=$ área total da bacia (HORTON, 1945). A delimitação das sub-bacias hidrográficas foi obtida a partir do MDE aprimorado. O MDE-SRTM foi utilizado para a extração manual dos lineamentos estruturais por meio de feições do relevo como a rede de drenagem e os alinhamentos das serras em escala de 1:100.000, em cada unidade geológica e a partir do comprimento máximo $\left(\mathrm{L}_{\max }\right)$ das lagoas alongadas e coalescentes. Os diagramas em roseta representativos das orientações dos lineamentos para cada grupo relacionado acima foram obtidos por 
análise automática com o aplicativo Polar Plots ArcGis Extension, que forneceu também a direção média dos lineamentos (JENNESS, 2014).

\section{Resultados}

\section{Superfície de Tendência}

As Superfícies de tendência de graus 1 a 9 foram obtidas a partir do MDE-SRTM original (Figura 2). O teste estatístico $\mathrm{R}^{2}$, de comparação entre as variâncias das superfícies simplificadas e os dados corrigidos, apontou a superfície de quinta ordem com melhor ajuste mínimo para o sistema lacustre. Tal superfície indica que as variáveis da superfície de tendência explicam 94\% dos dados da imagem original (Tabela 1).

A área de estudo possui grande extensão (8.272 $\mathrm{km}^{2}$ ) e uma amplitude altimétrica de apenas 110 metros (Figura 2a). A rede de drenagem é pouco desenvolvida e a maioria dos canais é intermitente, com um expressivo sistema lacustre com mais de 2.000 lagoas, situado numa zona de acumulação de sedimentos. Logo, a análise da superfície de tendência desta região possibilitou a separação de dados mapeáveis em duas componentes, sendo uma de natureza regional (Figura $2 b$ ) e outra que revelou as flutuações locais, representadas pelos valores residuais (Figura 2c).

Tabela 1: Coeficiente de ajuste $\left(\mathbf{R}^{2}\right)$ para o grau do polinômio utilizado para o cálculo da superfície de tendência.

\begin{tabular}{c|c}
\hline GRAU DO POLINÔMIO & AJUSTE DOS DADOS $\left(\mathbf{R}^{2}\right)$ \\
\hline 1 & 0,85 \\
\hline $2 \circ$ & 0,86 \\
\hline $3 \circ$ & 0,78 \\
\hline 40 & 0,90 \\
\hline $5 \circ$ & 0,94 \\
\hline 60 & 0,77 \\
\hline 70 & 0,72 \\
\hline 80 & 0,77 \\
\hline $9 \circ$ & 0,77 \\
\hline
\end{tabular}
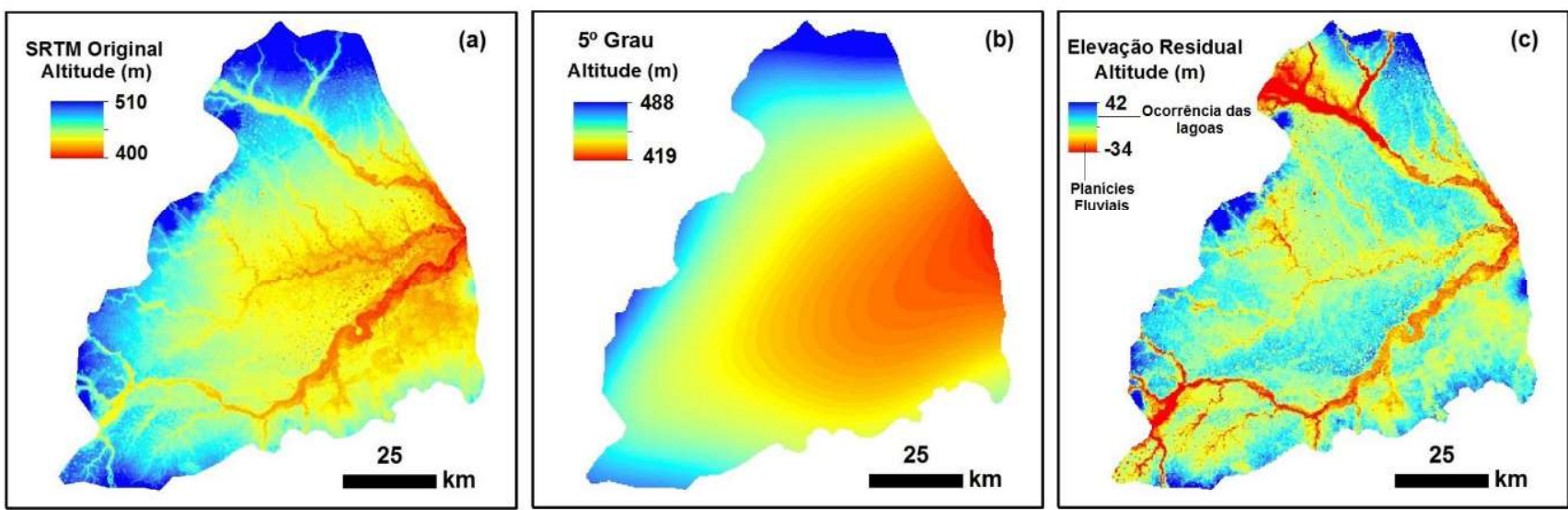

Figura 2 - (a) MDE-SRTM original; (b) MDE resultante do cálculo de superficie de tendência com polinômio de $5^{\circ}$ grau; e (c) MDE aprimorado.

A imagem realçada com os valores residuais (Figura 2c) possibilitou a demarcação dos limites topográficos entre os rios Preto, Camboeiro e Grande, por meio dos resíduos positivos de difícil percepção na imagem original. Esta delimitação tornou-se útil para o cálculo de assimetria das bacias. Ressalta-se ainda que os valores negativos mostraram que os canais fluviais apresentam-se confinados em suas planícies aluviais atuais, mais baixas topograficamente que o nível das lagoas. 


\section{Assimetria de bacias e densidade de drenagem}

Visando o levantamento de dados que forneçam informações passíveis de interpretação, compreensão e análise da existência de controle tectônico na área de estudo, calculou-se, também, o fator de assimetria considerando-se a área de localização do sistema lacustre, englobando as baixas bacias dos rios Preto e Camboeiro e a média bacia do rio Grande. De acordo com Mantelli e Rossetti (2009), este fator é de grande aplicação no reconhecimento de terrenos que tenham passado por basculamentos de blocos, podendo indicar o sentido das movimentações, além de ser bastante eficiente ao possibilitar interpretações morfoestruturais para área de relevos muito baixos.

A variável densidade de drenagem pode ser correlacionada a dados geológico-estruturais. Os altos valores de densidade de drenagem refletem baixa capacidade de infiltração das litologias envolvidas, podendo refletir também uma retomada erosiva das formas de relevo ao longo de estruturas como descontinuidades e basculamentos provenientes de atividade tectônica recente (HIRUMA e PONÇANO, 1994).

A análise de assimetria revelou que as três porções das bacias hidrográficas investigadas são fortemente assimétricas (Figura 3). A densidade de drenagem é dominantemente baixa, porém com áreas localizadas onde a densidade é baixa ou muito baixa (Figura 3).

A baixa bacia do rio Preto apresentou fator de assimetria $\mathrm{AF}=24,23$ em função de a área da direita ser significativamente menor que a área da esquerda. Além disso, os cursos d'água fluem dominantemente de noroeste para sudeste. Estes dois elementos sugerem um basculamento para direita no sentido NW-SE. $\mathrm{O}$ rio Preto apresenta inflexões quase ortogonais, abruptas, mudando entre as direções sudeste e nordeste. Entre as duas inflexões o canal percorre um trecho de aproximadamente $8 \mathrm{~km}$ no sentido nordeste e retorna abruptamente para sudeste onde deságua no rio Grande.

A bacia do baixo rio Camboeiro apresentou fator de assimetria $\mathrm{AF}=21,59$, similar ao da bacia anterior. Pôde-se observar que todos os afluentes da margem esquerda fluem na mesma direção que os principais cursos d'água da bacia do rio Preto, de NW-SE. Próximo às suas nascentes e por um trecho de aproximadamente
$30 \mathrm{~km}$ o rio Camboeiro possui esta mesma direção, mudando seu curso abruptamente para nordeste até desaguar no rio Grande, sendo a mesma direção do seu único afluente da margem direita. Ocorre uma inflexão inversa em um dos seus afluentes da margem esquerda.

A média bacia do rio Grande apresentou fator de assimetria distinto das demais, com o valor de $\mathrm{AF}=72,08$ indicando área da direita significativamente maior que a da esquerda. $\mathrm{O}$ rio Grande adentra a área do sistema lacustre com direção SW-NE, $20 \mathrm{~km}$ a jusante e sofre uma inflexão quase ortogonal para NW-SE, retornando abruptamente para a direção inicial, $30 \mathrm{~km}$ a jusante. Próximo à garganta da Serra do Boqueirão, seu curso é novamente invertido (NW-SE) em um pequeno trecho, e segue seu percurso até desaguar no rio São Francisco na direção SW-NE.

A densidade de drenagem revelou valores baixos para toda a área do sistema lacustre, $\mathrm{Dd}=0,21 \mathrm{~km} / \mathrm{km}^{2}$; $\mathrm{Dd}=0,15 \mathrm{~km} / \mathrm{km}^{2}$ e $\mathrm{Dd}=0,12 \mathrm{~km} / \mathrm{km}^{2}$ para a área dos rios Preto, Camboeiro e Grande respectivamente, o que condiz com o clima subúmido desta porção das bacias. No entanto, é nítido que existem dois compartimentos diferenciados tanto em relação à densidade de drenagem, quanto à direção do fluxo. $\mathrm{Na}$ área à esquerda da margem do rio Camboeiro a densidade de drenagem é superior $\left(\mathrm{Dd}=0,19 \mathrm{~km} / \mathrm{km}^{2}\right)$ e praticamente toda a drenagem flui de NW-SE. Já na área da margem direita do rio Camboeiro a densidade de drenagem é significativamente inferior $\left(\mathrm{Dd}=0,11 \mathrm{~km} / \mathrm{km}^{2}\right)$ e o fluxo dos cursos fluviais seguem a direção preferencial de SW-NE. A partir das evidências da rede de drenagem a área em estudo foi compartimentada em dois domínios morfoestruturais: Domínio I (DI) - baixa bacia do rio Preto e área da margem esquerda da baixa bacia do rio Camboeiro, e Domínio II (DII) - área da margem direita do rio Camboeiro e média bacia do rio Grande (Figura 3).

\section{Morfometria do Sistema Lacustre}

Foram cartografadas 2.024 lagoas distribuídas nos domínios morfoestruturais $D I$ e $D I I$. A análise das morfologias lacustres a partir das imagens RapidEye visou classificar as lagoas em três classes, no que tange à sua forma: coalescente, alongada e circular, cujos exemplos mais representativos são mostrados na Figura 4. 
Santos G. B. \& Castro P. T. A.

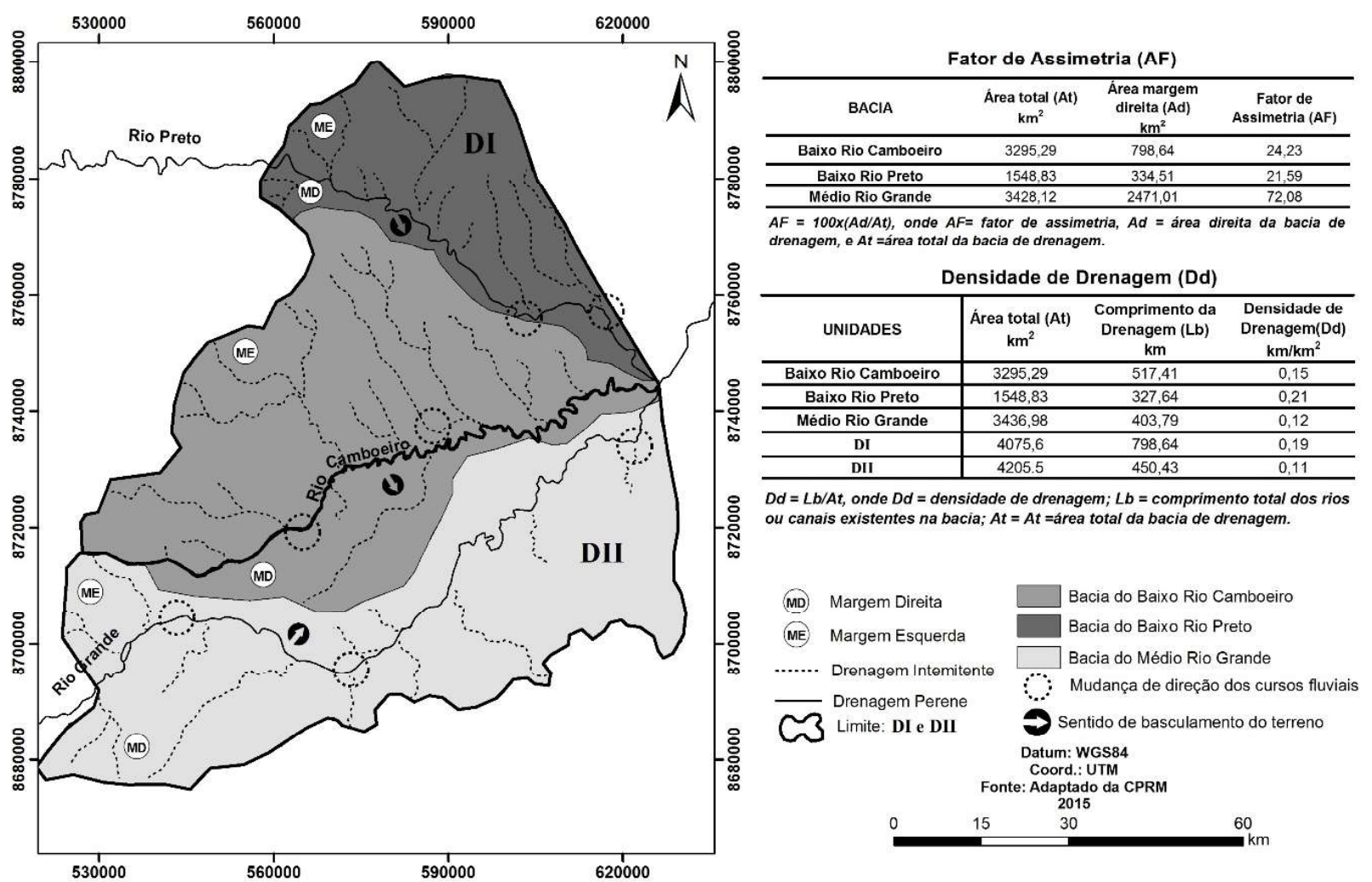

Figura 3 - Fator de assimetria (AF) e Densidade de drenagem (Dd) das baixas bacias dos rios Camboeiro e Preto e média bacia do rio Grande, na área do sistema lacustre.
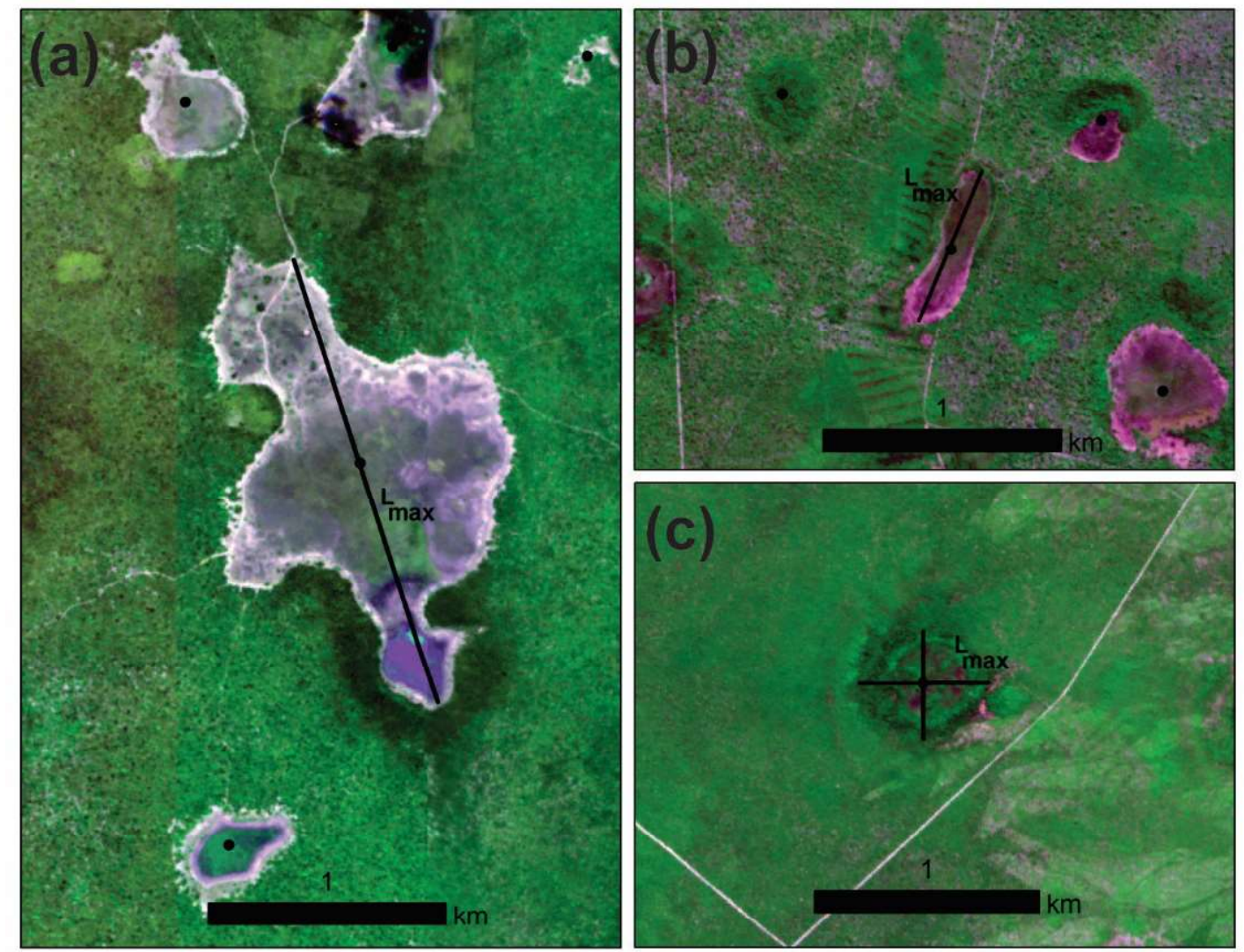

Figura 4 - Forma das lagoas: Coalescente: $F \geq 3$ (a); Alongada: 2,6 $\leq F<3$ (b); circular $2 \leq F \leq 2,59$ (c); Imagem RapidEye. 
A variável forma revelou que $92,3 \%$ das lagoas são circulares, seguidas por $5,8 \%$ de alongadas e apenas $1,8 \%$ de coalescentes representando $1.869,119$ e 36 lagoas respectivamente (Figura 5a). Quanto à distribuição das lagoas nas duas unidades morfoestruturais, o $D I$ registrou a menor ocorrência - 964 lagoas, dentre as quais 873 são circulares, 73 alongadas e 18 coalescentes. O DII apresentou o maior número de lagoas (1060), sendo 996 circulares, 46 alongadas e 18 coalescentes (Figura 5b).

Os valores de comprimento máximo (linha que une os dois pontos da lagoa mais afastados entre si) e da largura máxima (linha perpendicular ao comprimento máximo) revelaram que as lagoas do $D I$ são mais compridas e largas em relação às do DII. As tabelas $2 \mathrm{e} 3$ sintetizam os cálculos dos parâmetros morfométricos do sistema lacustre.
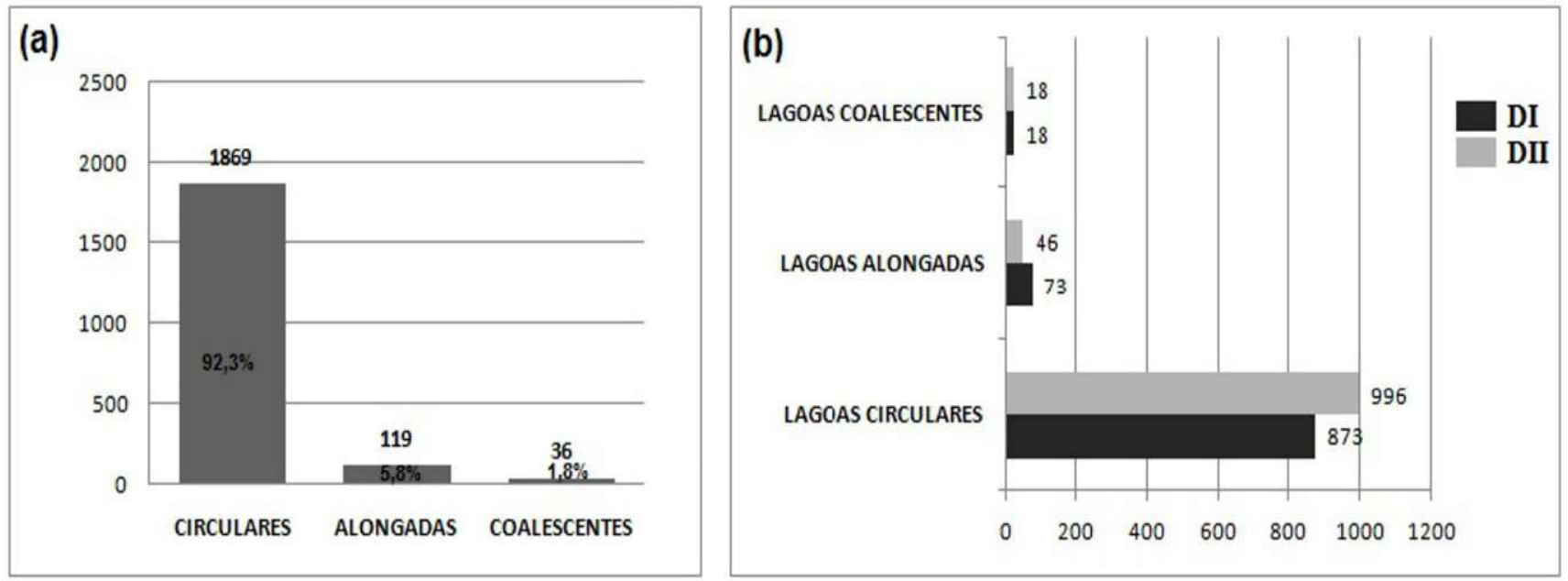

Figura 5 - Distribuição das lagoas quanto à forma (a) e por Domínios Morfoestruturais I e II (b).

Tabela 3: Parâmetros morfométricos das lagoas do Domínio II.

\begin{tabular}{|c|c|c|c|c|}
\hline \multicolumn{5}{|c|}{ LAGOAS DO DOMÍNIO II } \\
\hline \multicolumn{2}{|c|}{ Parâmetro Morfométrico } & Circulares & Alongadas & Coalescentes \\
\hline \multirow{3}{*}{$\begin{array}{c}\text { A } \\
\left(\text { Área: } \text { km²) }^{2}\right)\end{array}$} & Máxima & 0,74 & 0,9 & 0,66 \\
\hline & Mínima & 0,01 & 0,03 & 0,09 \\
\hline & Média & 0,11 & 0,19 & 0,26 \\
\hline \multirow{3}{*}{$\begin{array}{c}\mathrm{P} \\
\text { (Perímetro: km) }\end{array}$} & Máximo & 3,9 & 4,88 & 4,73 \\
\hline & Mínimo & 0,27 & 0,75 & 1,59 \\
\hline & Médio & 1,16 & 1,89 & 2,89 \\
\hline \multirow{3}{*}{$\begin{array}{c}\text { Forma } \\
\text { F }\end{array}$} & Máxima & 2,59 & 2,94 & 3,81 \\
\hline & Mínima & 2,03 & 2,60 & 3,01 \\
\hline & Média & 2,17 & 2,72 & 3,81 \\
\hline \multirow{3}{*}{$\begin{array}{c}\mathrm{L}_{\max } \\
\text { (Comprimento máximo: } \mathrm{m} \text { ) }\end{array}$} & Máximo & - & 1851,82 & 816,5 \\
\hline & Mínimo & - & 57,56 & 9,87 \\
\hline & Médio & - & 652,53 & 351,96 \\
\hline \multirow{3}{*}{$\begin{array}{c}\mathrm{La}_{\max } \\
\text { (Largura máxima: } \mathrm{m} \text { ) }\end{array}$} & Máxima & - & 844,61 & 1634,54 \\
\hline & Mínima & - & 104,98 & 325,07 \\
\hline & Média & - & 313,4 & 873,22 \\
\hline
\end{tabular}


Tabela 2 - Parâmetros morfométricos das lagoas do Domínio I.

\begin{tabular}{|c|c|c|c|c|}
\hline \multicolumn{5}{|c|}{ LAGOAS DO DOMÍNIO I } \\
\hline \multicolumn{2}{|c|}{ Parâmetro Morfométrico } & Circulares & Alongadas & Coalescentes \\
\hline \multirow{3}{*}{$\begin{array}{c}\text { A } \\
\left(\text { Área: } \mathrm{km}^{2}\right)\end{array}$} & Máxima & 1,57 & 0,82 & 1,31 \\
\hline & Mínima & 0,004 & 0,02 & 0,02 \\
\hline & Média & 0,14 & 0,25 & 0,38 \\
\hline \multirow{3}{*}{$\begin{array}{c}\mathbf{P} \\
\text { (Perímetro: km) }\end{array}$} & Máximo & 4,67 & 4,32 & 7,66 \\
\hline & Mínimo & 0,25 & 0,71 & 0,74 \\
\hline & Médio & 1,32 & 2,26 & 3,24 \\
\hline \multirow{3}{*}{$\begin{array}{c}\text { Forma } \\
\text { F }\end{array}$} & Máxima & 2,59 & 2,96 & 4,35 \\
\hline & Mínima & 2,03 & 2,6 & 3,01 \\
\hline & Média & 2,18 & 2,75 & 3,31 \\
\hline \multirow{3}{*}{$\begin{array}{c}\mathrm{L}_{\max } \\
\text { (Comprimento máximo: } \mathrm{m} \text { ) }\end{array}$} & Máximo & - & 1458,17 & 1336,24 \\
\hline & Mínimo & - & 217,85 & 88,02 \\
\hline & Médio & - & 787,32 & 423 \\
\hline \multirow{3}{*}{$\begin{array}{c}\mathrm{La}_{\max } \\
\text { (Largura máxima: } \mathrm{m})\end{array}$} & Máxima & - & 957,17 & 2079,39 \\
\hline & Mínima & - & 84,41 & 277,68 \\
\hline & Média & - & 382,52 & 953,74 \\
\hline
\end{tabular}

\section{Controle morfoestrutural e morfotectônico do sis- tema lacustre}

O uso de modelo de elevação regional (Figura 6) permitiu identificar que lineamentos de maior cumprimento estão dispostos preferencialmente na porção centro sul da bacia do rio Grande com direcionamento preferencial NE-SW relacionados às extensas áreas das litologias aflorantes do Grupo Urucuia, seguidos pelos lineamentos das formações São Desidério e Riachão das Neves. Na porção noroeste e nordeste prevalecem lineamentos de direção NW-SE. Os maiores comprimentos também estão relacionados ao Grupo Urucuia e às coberturas inconsolidadas. Neste setor prevalecem comprimentos menores relacionados às litologias das formações Formosa $\mathrm{e}$ Canabravinha, com pequena área de afloramentos. Na porção central, onde se encontram as coberturas inconsolidadas e o sistema lacustre, é possível observar que na região do $D I$ o comprimento acumulado dos lineamentos é superior $(437 \mathrm{~km})$ ao $D I I(333$ $\mathrm{km})$. O mesmo padrão ocorre para os lineamentos traçados no eixo longitudinal das lagoas alongadas e coalescentes nos dois domínios. Na porção leste da bacia os comprimentos acumulados dos lineamentos não são tão significativos, pois estão relacionados ao Grupo Santo Onofre, que comporta a Serra do Boqueirão, que é uma feição longilínea e ao Complexo Cristalândia do Piauí que possui uma pequena área de afloramento e ambos possuem lineamentos com direção preferencial de NW-SE.

Quanto à densidade de lineamentos, para as rochas paleoproterozoicas anteriores ao ciclo orogenético Brasiliano, observa-se para ambas a predominância de valores dos lineamentos traçados no quadrante NW, que abrange $72,7 \%$ no Complexo Cristalândia do Piauí com maior evidência das direções N30-40W, N20-10W e N40-50W, e 59,2\% para Formação Formosa, com maior evidência das direções N30-40W, N50-60W e N40-50W. As duas litologias possuem dispersão com pétalas secundárias no quadrante NE, sendo a Formação Formosa mais dispersa que o Complexo Cristalândia do Piauí, que apresenta uma concentração de lineamentos na direção N60-70W. Dividindo-se o número de lineamentos pela área de afloramento, a Formação Formosa possui maior densidade de lineamentos do que o Complexo Cristalândia do Piauí (Figura 7). 


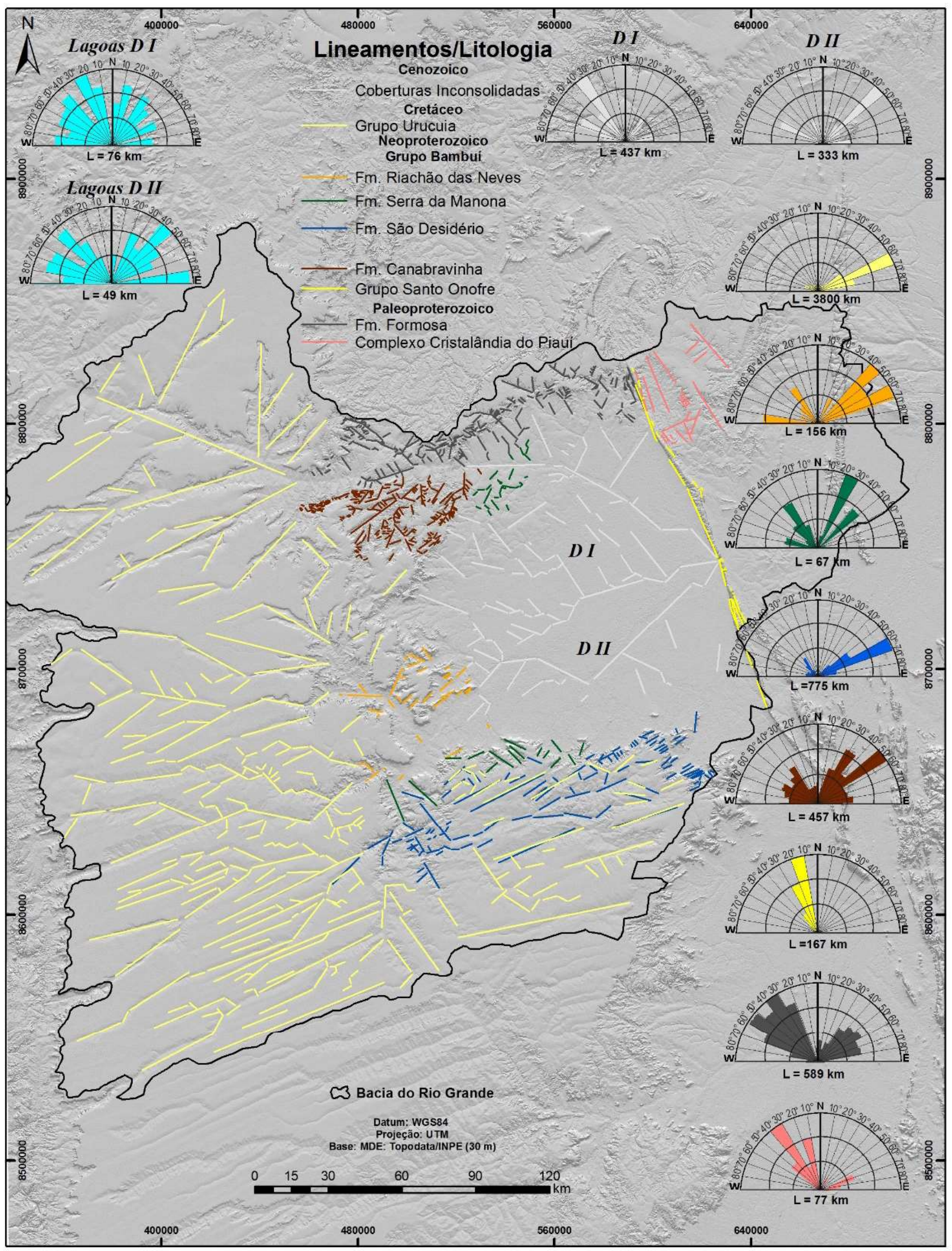

Figura 6 - Mapa de lineamentos e diagramas em rosetas com as tendências dos lineamentos dos comprimentos acumulados, interpretados a partir das litologias aflorantes na área de estudo, sobre imagem MDE-Topodata com relevo sombreado com iluminação a $0^{\circ}$ de azimute (Norte) e $45^{\circ}$ de elevação solar, com um exagero vertical de 3x em escala 1:1.000.000 na bacia do rio Grande. 

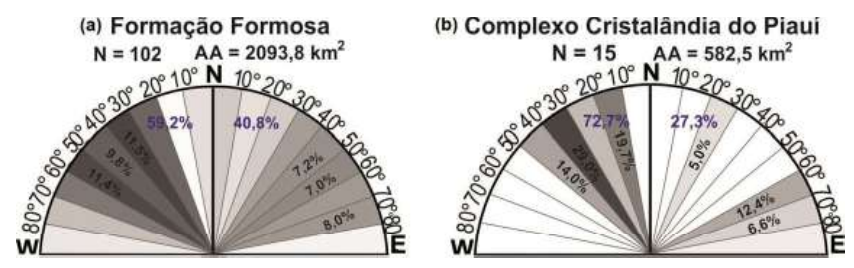

Figura 7 - Diagramas em roseta com os direcionamentos das densidades dos lineamentos das rochas paleoproterozoicas anteriores ao ciclo orogenético Brasiliano; (N=Número de Lineamentos e AA=Área de Afloramento).

O Grupo Santo Onofre é formado por rochas depositadas no aulacógeno neoproterozoico homônimo ( 900 Ma), com fechamento durante a orogênese Brasiliana ( $\sim 50 \mathrm{Ma})$, gerando uma faixa dobrada $\mathrm{e}$ estreita, representada pela Serra do Boqueirão com o menor afloramento na área de estudos, apenas 192,8 $\mathrm{km}^{2}$ (SCHOBBENHAUS, 1996). Por ser uma feição estreita e longilínea este grupo apresentou $100 \%$ de lineamentos no quadrante NW com $50,2 \%$ na direção N10-20W, 33,8\% N20-30W e 16\% N30-40W (Figura 8a). As rochas da Formação Canabravinha possuem a quinta maior área na região estudada. Estas rochas foram depositadas no neoproterozoico (850 e $600 \mathrm{Ma})$ em um rifte ou hemi-graben assimétrico (Bacia do Rio Preto) e metamorfisadas durante a orogênese Brasiliana (600-540 Ma) (CAXITO, 2012). Comparativamente, pode ser observada uma discrepância entre os resultados do Grupo Santo Onofre para esta unidade, onde o padrão observado apresenta maior volume de registros no quadrante NE $(57,8 \%)$ com direção principal N50$-60 \mathrm{E}$, mas apresenta dispersão com pétalas secundárias no quadrante NW, com direção principal N30-40W, se aproximando da direção principal do Grupo Santo Onofre (Figura 8b).
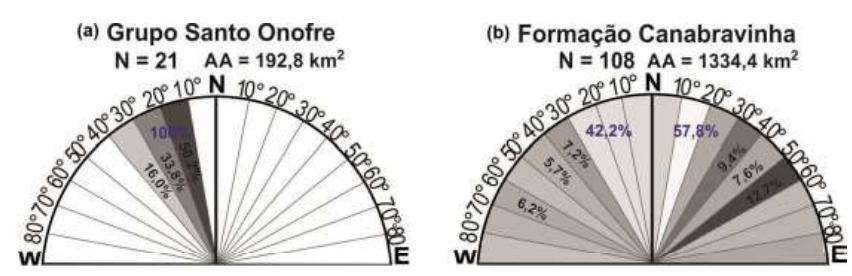

Figura 8 - Diagramas em roseta com os direcionamentos das densidades dos lineamentos das rochas neoproterozoicas formadas em riftes; ( $N=$ Número de Lineamentos e AA=Área de Afloramento).

As rochas do Grupo Bambuí fazem parte do $\mathrm{Su}$ pergrupo São Francisco, depositadas no final do neoproterozoico em bacias de antepaís, retrabalhadas no Ciclo Brasiliano (CASTRO, 2004). Esta região mostra deformação intensa na porção norte da área de estudos que vai progressivamente diminuindo para o sul até a predominância de camadas sub-horizontais (UHLEIN et al., 2011). $\mathrm{Na}$ área de estudos afloram rochas das formações Riachão das Neves $(971,2$ km²), São Desidério $(1063$ km²), e Serra da Mamona (1386,2 km²). As formações São Desidério $(80,2 \%)$ e Riachão das Neves $(63,7 \%)$ apresentam maior porcentagem de lineamentos no quadrante NE, onde a primeira apresenta direções principais de N60-70E, N50-60E e N80-90E, e a segunda N40-50E, N60-70E e N50-60E. Como se pode notar, o quadrante NW é caracterizado pelo menor volume de valores com direções principais de N20-30W e N30-40W para as formações São Desidério e Riachão das Neves, respectivamente (Figura 9a e c). Já a Formação Serra da Mamona apresenta uma leve superioridade e maior dispersão de lineamentos no quadrante NW (50,8\%), com destaque para a direção $\mathrm{N} 30-40 \mathrm{~W}$, porém maior densidade de lineamentos e possui direção N20-30E (22,4\%), concordante com as formações descritas anteriormente (Figura 9b).
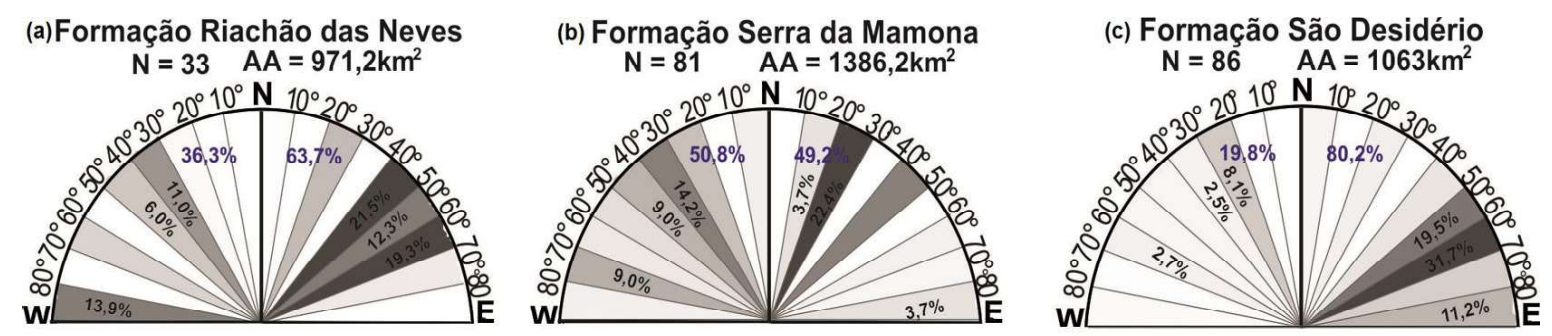

Figura 9 - Diagramas em roseta com os direcionamentos das densidades dos lineamentos das rochas do final do neoproterozoico em bacia de antepais; ( $N=$ Número de Lineamentos e AA=Área de Afloramento). 
As rochas do Grupo Urucuia possuem maior extensão na bacia do rio Grande $\left(44.763,2 \mathrm{~km}^{2}\right)$. Dividindo-se o número de lineamentos por sua área, obtêmse valores muito baixos, indicando pouca deformação nesta unidade (SPIGOLON e ALVARENGA, 2002). Estas rochas apresentam fraturamentos de direção NE, como reflexos de reativação tectônica cenozoica no Grupo Bambuí sob campo compressivo e com pequena movimentação (CAMPOS e DARDENNE, 1997). Os lineamentos traçados no Grupo Urucuia evidenciaram estes fraturamentos apresentando maior densidade no quadrante NE com direções principais de N60-70E, N70-80E e N50-60E (Figura 10).

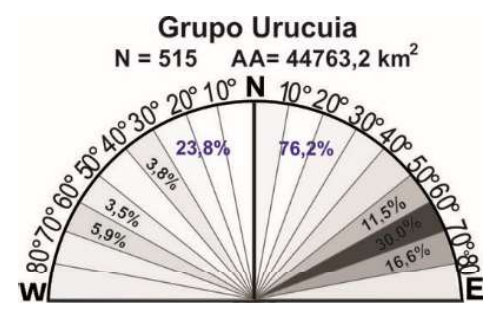

Figura 10 - Diagrama em roseta com os direcionamentos das densidades dos lineamentos das rochas mesozoicas da bacia Sanfranciscana; ( $N=$ Número de Lineamentos e AA=Área de Afloramento).

Ao analisar os lineamentos por domínio morfoestrutural, nota-se que o DI possui o maior número deles. Os que são baseados na drenagem apresentaram predominância de valores no quadrante NW, que abrange $66,5 \%$ dos lineamentos traçados, com direções principais de N30-40W, N60-70W e N40-50W (Figura 11a). Já aqueles das lagoas seguiram o mesmo padrão apresentando $57 \%$ no quadrante NW com direção principal N20-30W, mas com maior dispersão em outras direções, com destaque para a direção N10-20NE (Figura 11b).

Já a drenagem do DII apresenta comportamento inverso da anterior com maior número de lineamentos no quadrante NE $(62,2 \%)$, e maior concentração na direção N40-50NE. A segunda direção principal está no quadrante NW com valores de N60-70W (Figura 11c). As lagoas deste domínio possuem lineamentos praticamente uniformes para cada quadrante, sendo $52 \% \mathrm{NE}$ e $48 \% \mathrm{NW}$, com destaque para as direções N40-50E, N50-60E e N80-90E, e N40-50W, N60-70W e N70-80W (Figura 11d).

Com exceção dos grupos Santo Onofre (direção principal: NW-SE) e Urucuia (direção principal: SW$\mathrm{NE}$ ), observou-se em todas as unidades de área anali-

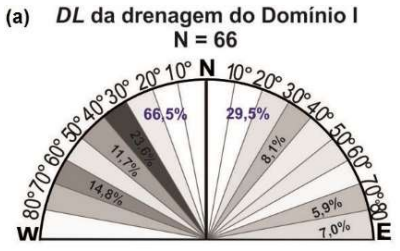

(b) $D L$ das lagoas do Domínio I

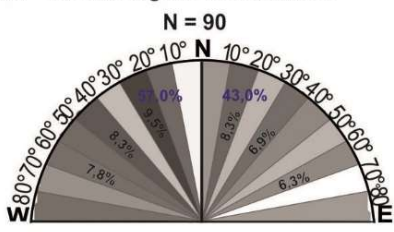

(c) DL da drenagem do Domínio II

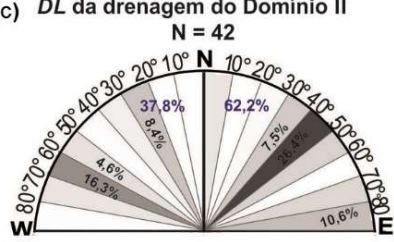

(d) DL das lagoas do Dominio II

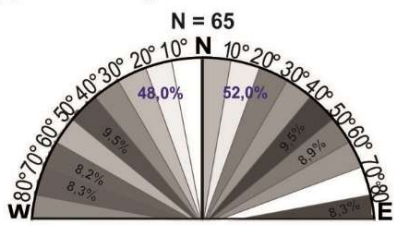

Figura 11 - Diagramas em roseta com as densidades dos direcionamentos dos lineamentos extraídos a partir das lagoas alongadas e coalescentes e da drenagem dos Domínios I e II; ( $D L=$ Densidade de Lineamentos).

sadas um padrão quase ortogonal para os lineamentos traçados, ou seja, possuem direções principais opostas em cada quadrante, atestando que existem duas direções principais de fraturas na região (uma NW-SE e outra SW-NE), e uma terceira menos significativa de direção $\mathrm{E}-\mathrm{W}$, registrada com maior intensidade nas rochas da Formação Riachão das Neves, na drenagem e nas lagoas do DII, na porção sudoeste do sistema lacustre.

O diagrama em rosetas da direção média dos lineamentos, apresentada no canto superior direito da figura 12 , mostra que as rochas paleoproterozoicas, associadas à riftes neoproterozoicos de bacia de antepaís, possuem direção média NW-SE evidenciando maior densidade de fraturamentos nesta direção, com exceção da Formação São Desidério que, com afloramentos na porção sul da área de estudos, apresentou direção média SW-NE, similar à drenagem próxima à sua área de exposição e das rochas mesozoicas do Grupo Urucuia.

Para atestar se os lineamentos das lagoas acompanham o mesmo padrão das anomalias de drenagem registradas na área de estudo, foram confeccionados diagramas em rosetas para as lagoas localizadas próximas a estas feições, representadas na figura 12 pelos números 1,2 , 3 e 4. As inflexões de drenagem no rio Preto de direção NW-SE para SW-NE são acompanhadas pelas mudanças dos lineamentos das lagoas, como atestam as rosetas 1 e 2. O mesmo ocorre para as anomalias de drenagem do rio Grande, representadas pelos números 3 e 4 . Portanto, tanto a rede de drenagem quanto os eixos longitudinais individuais das lagoas são concordantes com orientações principais de falhas regionais associados provavelmente a reativações de estruturas das rochas subjacentes. 

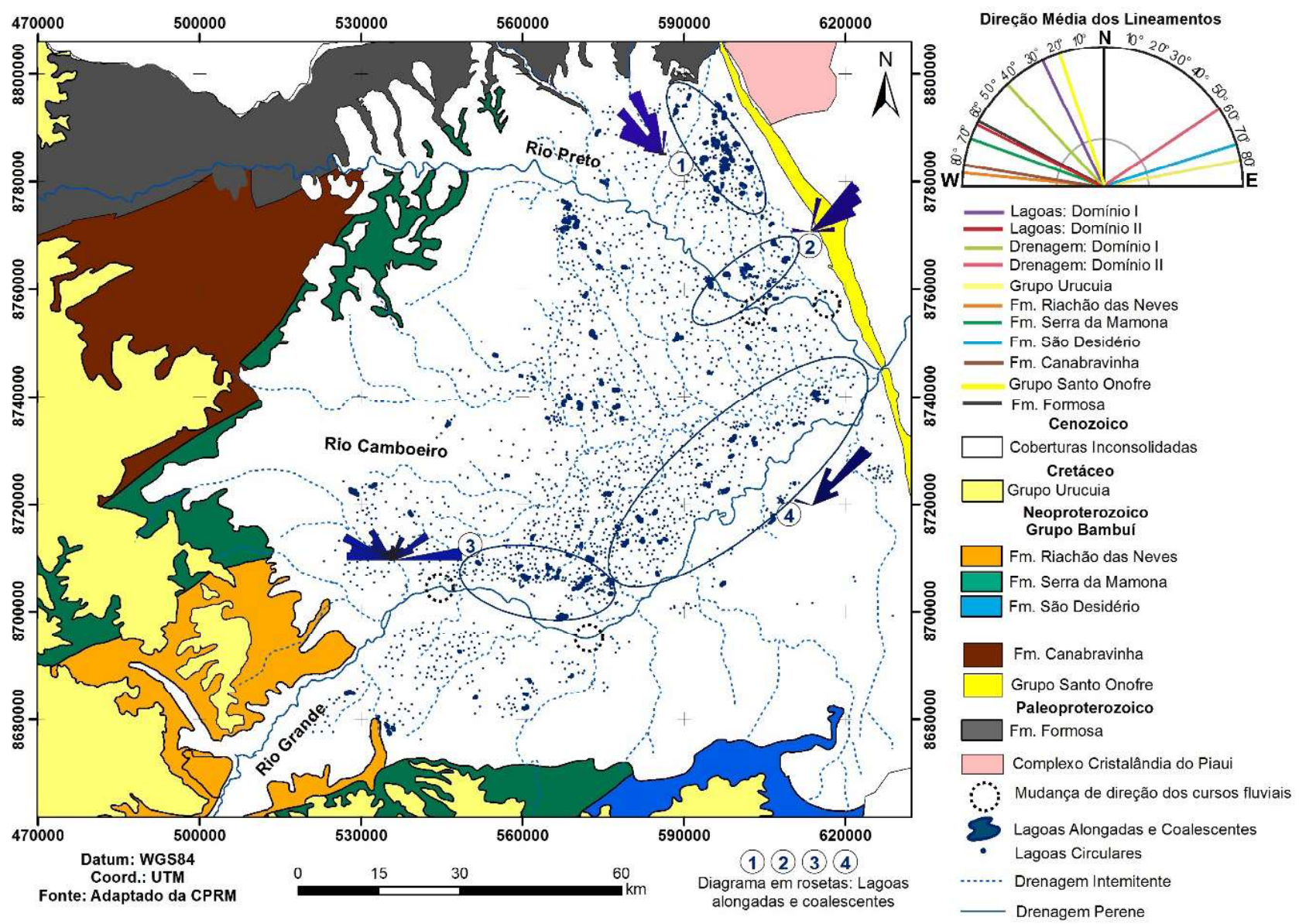

Figura 12 - Síntese da distribuição das lagoas e diagrama em rosetas da direção média dos lineamentos extraídos a partir das unidades geológicas e do eixo das lagoas alongadas e coalescentes na média bacia hidrográfica do rio Grande.

\section{Discussões}

A utilização de superfície de tendência para a delimitação dos limites topográficos das sub-bacias do médio rio Grande foi um método valioso para a análise geomorfológica da área corroborando os estudos de Zani et al. (2012), que apontaram a eficiência desta ferramenta para guiar investigações em ambientes de grandes dimensões, com pouca amplitude altimétrica e acumulação de sedimentos. Outra evidência ressaltada pelo MDE-SRTM aprimorado diz respeito às planícies aluviais atuais dos rios que drenam a região do sistema lacustre e que estão confinadas e não são conectadas atualmente aos lagos, podendo ser interpretado como evidência de mudanças de nível de bases regionais (FORTES et al., 2007; SILVA et al., 2007; SANTOS et al., 2008; MANTELLI e ROSSETTI, 2009).

A integração dos resultados de assimetria das bacias hidrográficas e de densidade de drenagem possi- bilitou a compartimentação da área do sistema lacustre em dois domínios estruturais, revelando um padrão de diferente contexto tectônico, confirmando a eficiência da análise de propriedades da drenagem em áreas de altitudes muito baixas, onde características ligadas ao relevo são inexpressivas, como atestam Mantelli e Rosseti (2009). A assimetria é caracterizada por maior área e densidade de drenagens no $D I$, com drenagens longas e unidirecionais a $\mathrm{SW}$, possivelmente relacionada à retomada erosiva, devido à reativação tectônica de estruturas brasilianas (MELO et al., 1993; HIRUMA e PONÇANO, 1994). Já no DII houve uma rarefação da drenagem e mudança para NE da direção do fluxo em regiões próximas aos afloramentos de rochas carbonáticas favoráveis à infiltração e que foram menos afetadas pela tectônica Brasiliana (UHLEIN et al., 2011; ROSSETTI, 2010; CRUZ e ALKMIM, 2006). As anomalias de drenagem consistem em mudanças abruptas, quase ortogonais nos cursos fluviais associadas ao controle 
tectônico. Tais feições foram identificadas nos dois domínios e podem estar relacionadas ao cruzamento dos sistemas de falhas NW-SE associadas ao aulacógeno Santo Onofre, e NE-SW relacionadas à Faixa Rio Preto (HIRUMA e PONÇANO, 1994; CRUZ e ALKMIM, 2006; UHLEIN et al., 2011).

A partir da análise morfométrica nos dois domínios morfoestruturais constatou-se que o $D I$ possui lagoas de maior extensão e menos numerosas, com maioria de forma alongada e coalescente, enquanto DII possui maior quantidade de lagoas circulares e coalescentes, porém menores. Silva (1984), ao estudar a morfometria das lagoas de Jaíba, na região norte de Minas Gerais, em um contexto litológico semelhante ao do médio rio Grande, atesta que a origem destas lagoas se dá por processos de carstificação (dolinas), associando as de maior diâmetro e alongadas às fraturas em metapelitos, e as circulares de menor diâmetro às rochas carbonáticas. De acordo com Piló (2000), as taxas de ampliação de dolinas estão relacionadas à eficiência hidrológica nas rotas de drenagem subterrânea. Portanto, no $D I$ a maior densidade de lineamentos proporcionou a maior taxa de ampliação e coalescência das lagoas, enquanto no $D I I$ as lagoas permanecem com formato circular. É provável que processos semelhantes ocorram no médio rio Grande, visto que existe a concentração de lagoas alongadas e coalescentes de maior diâmetro no $D I$, mais próximas de afloramentos de rochas metapelíticas, enquanto no DII predominam lagoas circulares, pois as alongadas e coalescentes são menores, estando mais próximas aos afloramentos de rochas carbonáticas menos afetadas pela orogênese Brasiliana, portanto com deformações menos intensas (UHLEIN et al., 2011). Quanto à direção dos lineamentos, o $D I$ é marcado principalmente pelo encaixe da rede de drenagem na direção NW-SE, e provavelmente estão associados às reativações recentes de antigas falhas ligadas às deformações do Evento Brasiliano, o qual afetou unidades neoproterozoicas do Grupo Santo Onofre e do embasamento (Complexo Cristalândia do Piauí), produzidos por compressão ENE-WSW que levou à formação dos sistemas de dobras e de falhas reversas, de empurrão e transcorrentes, de direção (principalmente N20W) e posterior reativação com movimentação normal em regime distensivo (ARCANJO e BRAZ FILHO, 1994; SCHOBBENHAUS, 1996; CRUZ e ALKMIM, 2006). O DII possui drenagem com direção de fluxo NE-SW, e direção secundária E-W, coincidente com as direções das rochas da Formação São Desidério que afloram próximo a este setor do sistema lacustre. Estes lineamentos de direção NE-SW provavelmente estão associados às reativações de falhas resultantes da tectônica compressional brasiliana, e também à Faixa Rio Preto de direção NNW-SSE, o que gerou falhas de empurrão de direção NE-SW e que passaram por reativação tectônica cenozoica afetando as rochas do Grupo Bambuí com reflexos no Grupo Urucuia (ARCANJO e BRAZ FILHO, 1994; CAMPOS e DARDENNE, 1997; CAXITO, 2010).

Já os lineamentos das lagoas nos dois compartimentos do sistema lacustre possuem duas direções principais quase ortogonais sendo N20-30W e N1020E para as lagoas do $D I$, e N40-50E e N40-50W e uma direção secundária N80-90E para as lagoas do DII. Estas mudanças de direções nos lineamentos das lagoas estão possivelmente associadas ao cruzamento dos sistemas de falhas, pois se observou que nos pontos de anomalia de drenagem, a direção do eixo principal das lagoas acompanhou a inflexão dos canais fluviais, indicando controle neotectônico.

\section{Considerações Finais}

A utilização de ferramentas de sensoriamento remoto para aprimorar o MDE-SRTM para análise geomorfológica em áreas amplas e com pouca amplitude altimétrica mostrou-se bastante eficiente, servindo de base para as demais análises morfométricas. Os resultados revelaram que este sistema lacustre possui influência da neotectônica, fato corroborado por inúmeras feições tais como: assimetria de bacia, anomalias de drenagem acompanhadas por mudança de direcionamento do eixo longitudinal das lagoas, e confinamento dos canais fluviais em suas planícies aluviais. A integração dos dados morfoestruturais aqui elencados com informações geotectônicas da porção noroeste do Cráton do São Francisco permitiu a compartimentação do sistema lacustre em dois domínios morfoestruturais: o $D I$ à esquerda da margem do rio Camboeiro mostra um arranjo de estruturas nas direções NW-SE, provavelmente ligadas às reativações de falhas relacionadas ao contexto do aulacógeno de Santo Onofre. E o DII à direita da margem do mesmo rio revela um padrão quase ortogonal ao primeiro com estruturas possivelmente relacionadas às falhas associadas ao contexto tectônico da Faixa Rio Preto. 
Por meio da interpretação dos lineamentos morfoestruturais, baseada na rede de drenagem atual no eixo longitudinal das lagoas e nas rochas de contextos tectônicos distintos, foi possível concluir que o desenvolvimento da paisagem lacustre do médio rio Grande é controlado por fator tectônico como anteriormente sugerido por Caxito (2010) e Carvalho Júnior et al. (2014), e as interpretações relacionadas à morfometria das lagoas bem como da densidade de drenagem sugerem que a litologia (rochas pelíticas ou carbonáticas) possa atuar como condicionante hidrológico para os processos de dissolução das depressões e para o desenvolvimento das lagoas alongadas e coalescentes, mais frequentes no $D I$, ou das circulares mais frequentes no DII.

\section{Agradecimentos}

Os autores agradecem à UFBA e à Superintendência de Estudos Econômicos e Sociais da Bahia (SEI) pela concessão das imagens do satélite RapidEye. E à CAPES mediante concessão de Bolsa durante os dois primeiros anos de Doutorado do primeiro autor.

\section{Referências Bibliográficas}

ALKMIM, F. F. A Serra do Espinhaço e a Chapada Diamantina. In: HASUI, Y.; CARNEIRO, C. D. R.; BARTORELLI, A., ALMEIDA, F. F. M. Geologia do Brasil. São Paulo: Beca, 2012, v. 1, p. 236-244.

ALKMIM, F. F. O que faz de um cráton um cráton? O Cráton do São Francisco e as suas revelações Almeidianas ao delimitá-lo. In: MANTESSO-NETO, V.; BARTORELLI, A.; CARNEIRO, C. D. R.; BRITO-NEVES, B. B. Geologia do Continente SulAmericano: evolução da obra de Fernando Flávio Marques de Almeida. São Paulo: Beca, 2004. p. 17-35.

ALVES, R. R. Gênese e evolução da superfície quaternária no médio São Francisco: fatos e evidências na bacia do rio Grande - Bahia. Uberlândia, Instituto de Geografia, Tese de Doutorado, Universidade Federal de Uberlândia, 314p. 2011.

ARCANJO, J. B. A.; BRAZ FILhO, P. A. Programa Levantamentos Geológicos Básicos do Brasil. Curimatá Folha SC.23-Z-A. Corrente Folha SC.23-Y-B (Parcial) e XiqueXique Folha SC.23-Z-B (Parcial). Estados da Bahia e do Piauí. Escala 1:250.000. Brasília, CPRM, 1994. 84 p.

CAMPOS, J. E. G.; DARDENNE, M. A. Origem e Evolução Tectônica da Bacia Sanfranciscana. Revista Brasileira de Geociências. v. 27, n.3, p. 283-294, 1997.
CARVALHO JÚNiOR, O. A.; GUIMARÃES, R. F.; MONTGOMERY, D. R.; GILLESPIE, A. R.; GOMES, R. A. T.; DE SOUZA MARTINS, E.; SILVA, N. C. Karst depression detection using ALOS PRISM, ASTER and SRTM-derived digital elevation models in the Bambuí Group, Brazil, Remote Sensing, v. 6, p. 330-351, 2014.

CASTRO, P. T. A. Características estratigráficas e sedimentológicas dos conglomerados e rochas associadas da Formação Samburá (Grupo Bambuí), região do alto Rio São Francisco, SW do Cráton do São Francisco. Geo.br (Ouro Preto), n.1, p. 1-20, 2004.

CASTRO, S.S. O platô de Itapetininga e as formações superficiais, material de origem do Latossolo vermelho escuro orto. Faculdade de Filosofia, Letras e Ciências Humanas, Departamento de Geografia, Universidade de São Paulo, São Paulo, Dissertação de Mestrado. 1980.

CAXITO, F. A. Evolução tectônica da Faixa Rio Preto, Noroeste da Bahia/Sul do Piauí. Belo Horizonte, Universidade Federal de Minas Gerais, Instituto de Geociências, Dissertação de Mestrado, 151 p, 2010.

CAXITO, F. A.; UHLEIN, A.; SANGLARD, J. C. D. ; GONÇALVES-DIAS, T.; MENDES, M. C. O. Depositional systems and stratigraphic review proposal of the Rio Preto Fold Belt, northwestern Bahia/southern Piauí. Revista Brasileira de Geociências, v. 42, p. 523-538, 2012.

CHRistiansen, E. H.; HAMBlin, W. K. Dynamic Earth: An Introduction to Physical Geology. ed. Jones and Bartlett Publishers, Incorporated, 838p., 2014.

CORBELLA, H.; LARA H. L. Late Cenozoic Quaternary Volcanism in Patagonia and Tierra del Fuego. In: Rabassa J. (ed.) The Late Cenozoic of Patagonia and Tierra del Fuego. 1 ed. Amsterdam: Elsevier, p.: 95-120, 2008.

COSTA M. L; CARMO M. S.; BEHLING H. Mineralogia e geoquímica de sedimentos lacustres com substrato laterítico na Amazônia brasileira. Revista Brasileira de Geociências, v. 35 , p.165-176, 2005.

COTTON, A. Geomorphology. London, Witcombe \& Tombs Limited. 187p., 1968.

CRUZ, S. C. P.; ALKMIM, F. F. The tectonic interaction between the Paramirim Aulacogen and the Araçuaí belt, São Francisco craton region, Eastern Brazil. An. Acad. Bras. Cienc., v.78, n.1, p.151-173, 2006.

DOORNKAMP, J. C. Geomorphological approaches to the study of Neotectonics. Journal of the Geological Society of 
London, v.143, p. 335-342, 1986.

EGYDIO-SILVA, M. O sistema de dobramentos Rio Preto e suas relações com o Cráton São Francisco. São Paulo, Universidade de São Paulo, Instituto de Geociências, Tese de doutorado, 95 p, 1987.

FORTES, E.; VOLKMER, S.; STEVAUX, J. C.; MARQUES, A. J. Anomalias de drenagem e controles morfotectônicos da evolução dos terraços do baixo curso do rio Ivinhema MS. Geociências, v. 26, p. 249-261, 2007.

GASPAR, M. T. P. Sistema Aqüífero Urucuia: caracterização regional e propostas de gestão. Brasília, Universidade de Brasília, Instituto de Geociências, Tese de Doutorado, 204 p, 2006.

GHONEIM, E. Ibn-Batutah: a possible simple impact structure in southeastern Libya, a remote sensing study. Geomorphology, v.103, p. 341-350, 2009.

GROHMANN, C. H. Trend-surfaces analysis of morphometric parameters: A case study in southeastern Brazil. Computers \& Geosciences, v. 31, n. 8, p. 1007-1014, 2005.

GROHMANN, C. H.; RICCOMINI, C. Análise digital de terreno e evolução de longo-termo de relevo do centro-leste brasileiro. Geologia - USP, Série Científica, v. 12, n. 2, p. 129-150, 2012.

GROHMANN, C. H.; RICCOMINI, C.; ALVES, F. M. SRTMbased morphotectonic analysis of the Poços de Caldas Alkaline Massif, southeastern Brazil. Computers \& Geosciences, v. 33, n.1, p. 10-19, 2007.

HARDT, R. 2011. Da carstificação em arenitos. Aproximação com o suporte de geotecnologias. À propos de la karsification dans les grès. Traitement par les technologies SIG. Tese de Doutorado, Instituto de Geociências e Ciências Exatas, Universidade Estadual Paulista Julio de Mesquita Filho. Em co-tutela com Morphodynamique Continentale et Côtière, Laboratoire de Géologie, Université de Rouen, 224 p.

HASHIMOTO, A.; OGUCHI, T.; HAYAKAWA, Y.; LIN, Z.; SAITO, K.; WASKLEWICZ, T.A. GIS analysis of depositional slope change at alluvial-fan toes in Japan and the American Southwest. Geomorphology, 100, 120-130, 2008.

HAYAKAWA, E. H.; ROSSETTI, D. F. Caracterização da rede de drenagem da bacia do médio e baixo rio Madeira. Revista Brasileira de Geomorfologia, v.13, n. 4, p. 401-418, 2012.

HIRUMA, S. T.; PONÇANO, W. L. Densidade de Drenagem e sua relação com fatores geomorfopedológicos na área do alto Rio Pardo, SP e MG. Rev. IG, v.15, n.1/2, p.49-57, 1994.
HORTON, R. E. Erosional development of streams and their drainage basins hidrophysical approach to quantitative morphology. Bulletin of American Geological Society, v. 56, n.3, p. 275-330, 1945.

HUANG, Hsin-Hui. Geomorphologic investigations on karst terrain: A GIS-assisted case study on the island of Barbados. Thesis, McGill University, Montreal, 94 p., 2007.

IBGE, Instituto Brasileiro de Geografia e Estatística. Manual Técnico da Vegetação Brasileira. Rio de Janeiro: IBGE, 1992. $92 \mathrm{p}$.

JENNESS, J. Polar Plots and Circular Statistics: Extension for ArcGis. Jenness Enterprises. Disponível em: http://www. jennessent.com/arcgis/Polar_Plots.htm. 2014.

LATRUBESSE, E. M.; NELSON, B.W. Evidence for Late Quaternary Aeolian Activity in the Roraima-Guyana Region. Catena, v.43, p.63-80, 2001.

MACIEL FILHO, C. L.; NUMMER, A. V.; SILVÉRIO DA SILVA, J. L.; SANGOI D. S.; DESCOVI FILHO L. L. V. Feições de carste sobre a formação Serra Geral na região de Vacaria, RS, e Lages, SC. Caminhos de Geografia (UFU), v.14, p. 97-208, 2013.

MANTELLI, L. R., ROSSETTI, D. F. Significado tectônico de lineamentos de drenagem no sudoeste da ilha do Marajó. Revista Brasileira de Geociências, v.39, n.1, p.42-54, 2009.

MATEUS, A. C. C.; OLIVEIRA, F. SOARES DE; VARAJÃO, A. F. D. C.; SOARES, C. C. V.; SCHÜNEMANN, A. L. Gênese de depressões fechadas em vertentes associadas à couraça aluminosa na porção sul da Serra do Caparaó, Minas Gerais/ Espírito Santos. Revista Brasileira de Geomorfologia, v. 17, n.2, p.369-387, 2016.

MELO, M. S.; STEIN, D. P.; PONÇANO, W. L.; BISTRICHI, C. A. Neotectônica da Área do Alto Rio Pardo (SP e Mg), Revista IG, v.14, n.1, p. 27-38, 1993.

MOREIRA M. C.; SILVA, D. D. Atlas hidrológico da bacia hidrográfica do rio Grande. Gazeta Santa Cruz, Barreiras, 80 p. 2010.

NASCIMENTO, P.; MORAIS F. Análise morfométrica em Ipucas em carste encoberto na Depressão do Médio Araguaia, estado do Tocantins. In: Simpósio Nacional de Geomorfologia: Geomorfologia e eventos catastróficos: passado, presente e futuro, 9, Anais, v.1: p. 1-6, 2012.

NORONHA, S. E. Caracterização dos Ecossistemas Lacustres Sob Substrato Laterítico na Região de Palmeirópolis TO. Universidade de Brasília, Departamento de Geografia, 
Dissertação de Mestrado, 81 p. 2009.

PEREIRA M. C.; RODET, J. G. M. A.; SALGADO A. A. R. Aspectos genéticos e morfológicos das cavidades naturais da Serra da Piedade, Quadrilátero Ferrífero/MG. Revista Brasileira de Geomorfologia, v. 13, n.4, p.465-476, 2012.

PILLMORE C. L. Deflation origin of Adams and Bartlett Lake Basins, Vermejo Park New Mexico. In: Ewing, R. C. e Kues, B.S.(eds.), Guidebook of Vermejo Park, northeastern New Mexico. Geological Society Guidebook, New Mexico, v.27, p.121-124, 1976.

PILÓ, L. B. Geomorfologia Cárstica. Revista Brasileira de Geomorfologia, v. 1, n. 1, p. 88-102, 2000.

ROSSETTI, D. F. Tectonic control on the stratigraphyframework of Late pleistocene and holocene deposits in Marajó Island, State of Pará, eastern Amazonia. Acad Bras Cienc, v. 82, p. 439-450, 2010.

ROSSETTI, D. F.; BEZERRA, F. H.; GÓES A. M.; VALERIANO M. M.; ANDRADES-FILHO C. O.; MITTANI J. C. R., TATUMI S. H.; BRITO-NEVES B. B. Late Quaternary sedimentation in the Paraíba Basin, Northeastern Brazil: landform, sea level and tectonics in Eastern South America passive margin. Palaeogeography, Palaeoclimatology, Palaeoecology, v. 300, p.191-204, 2011.

ROSSETTI, D. F.; VALERIANO, M. M. Evolution of the lowest Amazon basin modeled from the integration of geological and SRTM topographic data. Catena. v.70, p. 253-265, 2007.

SAADI, A. Ensaio sobre a morfotectônica de Minas Gerais. Belo Horizonte. Programa de Pós-Graduação em Geografia, Universidade Federal de Minas Gerais, Belo Horizonte, Tese Professor Titular. 285p., 1991.

SALLUN FILHO, W; KARMANN I. Dolinas em arenitos da Bacia do Paraná: evidências de carste subjacente em Jardim (MS) e Ponta Grossa (PR). Revista Brasileira de Geociências, v.37, p. 551-564, 2007.

SANTOS, M. L.; STEVAUX, J. C.; GASPARETTO, N. V. L.; SOUZA FILHO, E. E. Geologia e Geomorfologia da planície do rio Ivaí-PR. Revista Brasileira de Geomorfologia, v. 9, p. 23-34, 2008.

SCHOBBENHAUS, C. As tafrogêneses superpostas Espinhaço e Santo Onofre, estado da Bahia: Revisão e novas propostas. Revista Brasileira de Geociências.v.26, n. 4, p. 265- 276, 1996.
SILVA, A. B. Análise morfoestrutural, hidrogeológica e hidroquímica no estudo do aqüífero cárstico do Jaíba, norte de Minas Gerais. São Paulo, Universidade de São Paulo, Instituto de Geociências, Tese de doutorado, 190 p, 1984.

SOUZA FILHO, P. W. M.; QUADROS, M. L. E. S.; SCANDOLARA, J. E.; SILVA FILHO, E. P.; REIS, M. R. Compartimentação morfoestrutural e neotectônica do sistema fluvial Guaporé-Mamoré-Alto Madeira, Rondônia-Brasil. Revista Brasileira de Geociências. v. 29, n.4, p.469-476, 1999.

SPIGOLON, A. L. D.; ALVARENGA, C. J. S. Fácies e elementos arquiteturais resultantes de mudanças climáticas em um ambiente desértico: Grupo Urucuia (Neocretáceo), Bacia Sanfranciscana, Brasil. Revista Brasileira de Geociências. v. 32, n.4, p. 397-405, 2002.

STEWART, I. S.; HANCOCK, P. L. Neotectonics. In: HANCOCK, P. L. (Ed.) Continental Deformation. Oxford: Pergamon Press, 1994. p. 370-409.

STRASKRABA, M.; GNAUCK, A. Aquatische Okosysteme: Modellierung und Simulation. Gustav Fischer Verlag, Stuttgart, p. 287-311, 1982.

SUMMERFIELD, M. A. Global Geomorphology. New York, Jonh Wiley \& Sons, 537p., 1991.

UHLEIN A.; ALVARENGA, C. J. S.; TROMPETTE; R. R.; DUPONT, H. S. J. B.; EGYDIO-SILVA, M.; CUKROV, N.; LIMA, O. N. B. Glaciação neoproterozóica sobre o cráton do São Francisco e faixas dobradas adjacentes. In: MANTESSO-NETO, V.; BARTORELLI, A.; CARNEIRO, C.D.R.; BRITO-NEVES, B.B. Geologia do Continente Sul-Americano: evolução da obra de Fernando Flávio Marques de Almeida. São Paulo: Beca, 2004. p.539-553.

UHLEIN, A.; CAXITO, F. A.; SANGLARD, J. C. D.; UHLEIN, G. J.; SUCKAU, G. L. Estratigrafia e tectônica das faixas neoproterozóicas da porção norte do Cráton do São Francisco. Geonomos. v. 19, n. 2, p. 8-31, 2011.

VALERIANO, M. M.; ROSSETTI, D. F. Topodata: Brazilian full coverage refinement of SRTM data. Applied Geography, v. 32, p. 300-309, 2012.

ZANI H.; ASSINE, M. L.; MCGLUE, M. M. Remote sensing analysis of depositional landforms in alluvial settings: Method development and application to the Taquari megafan, Pantanal (Brazil). Geomorphology, v. 161-162, p. 82-92, 2012. 